\title{
Epidemiology of Psoriatic Arthritis
}

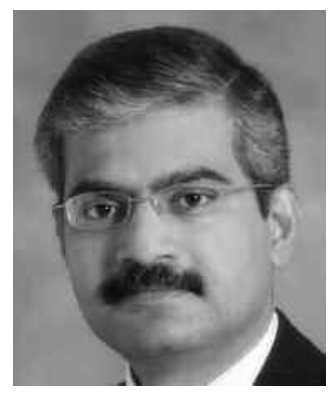

Is the epidemiology of psoriatic arthritis (PsA) truly changing? Is the incidence indeed rising? If so, what are the possible reasons? Is it because psoriasis is becoming more prevalent? Clearly, genetic factors do not change over a few decades; therefore, how are environmental factors influencing the disease? These are the questions that spring to mind on reading the article by Wilson, et al in this issue of The Journal ${ }^{1}$.

PsA is a form of seronegative spondyloarthritis associated with psoriasis ${ }^{2}$. Although the occurrence of arthritis associated with psoriasis was probably recognized as early as 1818 , it was as recently as 1964 that PsA was recognized by the American Rheumatism Association (American College of Rheumatology) as a distinct clinical entity ${ }^{3}$. And it was as late as 1996 that studies on prevalence and incidence of PsA were published ${ }^{4}$. A recent review of studies undertaken to December 2006 has shown widely varying estimates of incidence and prevalence ${ }^{4}$. While estimates obtained from studies conducted within Europe and North America vary significantly, the most striking difference is between Europe and Japan. The incidence in Europe and North America ranged between 3 and 23.1 cases $/ 10^{5}$, whereas that in Japan was only 0.1 cases $/ 10^{5}$. Similarly, the prevalence in Europe and North America ranged between 20 and 420 cases $/ 10^{5}$, but in Japan it was only $1 / 10^{5}$. This large difference is most likely due to differences in ethnicity, since low prevalence of other spondyloarthropathies in Japan has also been reported ${ }^{5}$.

The challenges in conducting epidemiological studies in PsA neatly elucidated in 1994 by O'Neill and Silman are still relevant ${ }^{3}$. The most important problem identified was lack of validated classification criteria. It should be noted, however, that although a number of proposed classification criteria were available, until now most epidemiological studies have used the co-occurrence of psoriasis and arthritis or the European Spondylarthropathy Study Group (ESSG) criteria to identify cases of $\mathrm{PsA}^{4,6}$. Use of these criteria may not be appropriate because even if patients with inflammatory arthritis were correctly identified, not all patients with psoriasis and inflammatory arthritis have PsA. Moreover, the ESSG criteria have poor sensitivity ${ }^{7}$. The original criteria for PsA proposed by Moll and Wright in 1973 were meant to be diagnostic rather than classification criteria ${ }^{8}$. A number of classification criteria have since been proposed but none have been universally accepted ${ }^{7}$. Recently, the ClASsification criteria for Psoriatic ARthritis (CASPAR) Study Group compared the performance characteristics of these criteria and developed a new set ${ }^{7}$. These new classification criteria were developed in patients with long-standing disease and in the original study had specificity of $98.7 \%$ and sensitivity of $91.4 \%$. Subsequently, the criteria were shown to have excellent sensitivity in both early and late disease ${ }^{9}$. The CASPAR criteria were found to have been developed using sound measurement principles although they remain to be fully validated ${ }^{10}$. In fact, modifications of these criteria for epidemiologic studies have already been proposed ${ }^{11}$. One major issue yet unresolved is the definition of "inflammatory musculoskeletal disease." The CASPAR criteria can only be applied to those fulfilling this mandatory criterion. Identifying inflammatory musculoskeletal disease is usually not difficult for rheumatologists, but may be a stumbling block for wider application of criteria by physicians, whether in the community or in dermatology practices. In spite of this drawback, CASPAR criteria have been recognized to be simple and easy to apply to data collected retrospectively ${ }^{9,12}$. Moreover, using these criteria it is possible to classify patients as having PsA even when they do not have current, past, or family history of psoriasis.

In this issue of The Journal, using the resources of the Rochester Epidemiology Project and applying the CASPAR classification criteria, Wilson and colleagues have shown that the incidence of PsA has been rising over 30 years in males and females in Rochester, Minnesota, USA ${ }^{1}$. The fol-

See Time trends in epidemiology and characteristics of PsA over 3 decades, page 361

Personal non-commercial use only. The Journal of Rheumatology Copyright (c) 2009. All rights reserved. 
lowing are key findings of their studies: (1) overall age- and sex-adjusted annual incidence of PsA per 100,000 was 7.2, with a higher incidence in males than females; (2) the ageand sex-adjusted incidence of PsA per 100,000 increased significantly from 3.6 between 1970 and 1979 to 9.8 between 1990 to 2000; (3) the point prevalence per 100,000 was 158 in 2000, with a higher prevalence in males than females; and (4) at incidence, most PsA subjects had oligoarticular involvement with enthesopathy. This is remarkable, since using the same resources the same research group has shown that the incidence and prevalence of rheumatoid arthritis is decreasing ${ }^{13}$. Interestingly, using the same resources, Shbeeb and colleagues showed in 2000 that the overall incidence of PsA was 6.59 per 100,000 between 1982 and 1991, and the point prevalence on January 1,1992 , was 1 per $1000^{14}$, which is similar to the estimate in the current study ${ }^{1}$ for that decade. The current study differs from the 2000 study in that patients were classified as having PsA based on the CASPAR criteria, and thus 30 additional subjects were identified who did not have cutaneous psoriasis. The criteria were applied to data collected from charts using a standardized data abstraction form. However, applying the criteria on data collected from charts has major limitations. The CASPAR criteria can only be applied to patients with "inflammatory articular disease (joint, spine, entheseal)". As mentioned above, inflammatory articular disease might be difficult for general practitioners and dermatologists to recognize. In fact, the CASPAR study group opined that it is not possible to apply the results of their study to the general population or to other clinical populations such as dermatology clinic populations, and the criteria have to be validated in these populations ${ }^{7}$. In addition, in the current study ${ }^{1}$, the radiographic criterion was applied rather loosely, as "radiographic evidence of psoriatic bone changes of the hand or foot such as joint space narrowing, juxtaarticular new bone formation, ankylosis, spondylitis, joint erosions, periostitis, osteolysis, and sacroiliitis on plain films at time of PsA diagnosis" rather than "radiographic evidence of juxtaarticular new bone formation, appearing as ill-defined ossification near joint margins (but excluding osteophyte formation) on plain radiographs of the hand or foot," which was the only radiographic feature found to have value in discriminating PsA from other inflammatory arthritides ${ }^{7}$. Most included cases satisfied criteria of current psoriasis and negative rheumatoid factor; however, the impact of misclassification based on radiographic criterion is not known but is likely to be low. The results also support the notion that early PsA presents as enthesitis and oligoarthritis and progresses over time to polyarticular disease.

Thus, if PsA incidence is truly increasing over the last 3 decades, what are the reasons? One obvious reason is better recognition of the condition by physicians in more recent years. Genetic or ethnicity related factors are unlikely to be responsible for the observed change since there has not been any significant immigration or emigration from this "captive" population. It would be interesting to study how environmental factors have changed over the years to give us an explanation. However, such studies are best done prospectively. Corticosteroid use, pregnancy, trauma, and rubella vaccination have been shown to be most important ${ }^{15,16}$.

What is the relationship between PsA and psoriasis? The estimated prevalence of PsA in patients with psoriasis ranges from $6 \%$ to $42 \%{ }^{2}$. To my knowledge, there are no published studies on the incidence of PsA in patients with psoriasis. Since most patients with PsA have psoriasis, if the prevalence of PsA is increasing, it is likely that the prevalence of psoriasis is also increasing. Wilson and colleagues have investigated this and have found similar increasing prevalence of psoriasis in Rochester ${ }^{17}$. They have also investigated predictors for development of PsA in psoriasis, and it will be interesting to see what the results are ${ }^{17}$. Thus, the prevalence of both psoriasis and PsA is increasing, and environmental rather than genetic factors are probably responsible.

In contrast to reports from a Canadian referral-clinic population $^{18}$, excess mortality in the Rochester cohort could not be demonstrated. The authors suggest that subjects with severe PsA are probably under-represented in this cohort compared to the Canadian cohort. Interestingly, an update from the Canadian cohort showed that the mortality risk has improved in recent decades. This could be due to earlier diagnosis and more aggressive treatment in the more recent followup period ${ }^{18}$. It should be noted, however, that in the current study ${ }^{1}, 32 \%$ had radiographic erosions and $13 \%$ had osteolysis, indicating severe disease. The results are consistent with a similar population-based study using the Norfolk Arthritis Register ${ }^{19}$, and a hospital-based early arthritis clin$\mathrm{ic}^{20}$, where erosions were detected at baseline in $36.7 \%$ and $27 \%$ of available radiographs, respectively.

Thus, this population-based study on PsA in a welldefined geographic location has provided us with some very interesting results that need to be replicated in other comparable cohorts. This knowledge, coupled with knowledge from future genetic and environmental studies, will help us better understand the epidemiology, genetics, and genetic epidemiology of both psoriasis and PsA.

\footnotetext{
VINOD CHANDRAN, DM,

Division of Rheumatology,

Department of Medicine,

University of Toronto,

Clinical Research Fellow, University of Toronto, Toronto, Ontario, Canada
}

Address reprint requests to Dr. Chandran, Centre for Prognosis Studies in the Rheumatic Diseases, Toronto Western Hospital, 1E 412,

399 Bathurst Street, Toronto, ON M5T 2S8, Canada.

E-mail:vinod.chandran@uhnres.utoronto.ca 
Supported by a Canadian Institutes of Health Research-Clinical Research Initiative Fellowship and the Krembil Foundation.

\section{REFERENCES}

1. Wilson FC, Icen M, Crowson CS, McEvoy MT, Gabriel SE, Maradit Kremers H. Time trends in epidemiology and characteristics of psoriatic arthritis over 3 decades: A populationbased study. J Rheumatol 2009;36:361-7.

2. Gladman DD, Antoni C, Mease P, Clegg DO, Nash P. Psoriatic arthritis: epidemiology, clinical features, course, and outcome. Ann Rheum Dis 2005;64 Suppl 2:ii14-7.

3. O'Neill T, Silman AJ. Psoriatic arthritis. Historical background and epidemiology. Baillieres Clin Rheumatol 1994;8:245-61.

4. Alamanos Y, Voulgari PV, Drosos AA. Incidence and prevalence of psoriatic arthritis: a systematic review. J Rheumatol 2008; 35:1354-8.

5. Hukuda S, Minami M, Saito T, et al. Spondyloarthropathies in Japan: nationwide questionnaire survey performed by the Japan Ankylosing Spondylitis Society. J Rheumatol 2001;28:554-9.

6. Dougados M, van der Linden S, Juhlin R, et al. The European Spondylarthropathy Study Group preliminary criteria for the classification of spondylarthropathy. Arthritis Rheum 1991;34:1218-27.

7. Taylor W, Gladman D, Helliwell P, Marchesoni A, Mease P, Mielants H; CASPAR Study Group. Classification criteria for psoriatic arthritis: development of new criteria from a large international study. Arthritis Rheum 2006;54:2665-73.

8. Moll JM, Wright V. Psoriatic arthritis. Semin Arthritis Rheum 1973;3:55-78

9. Chandran V, Schentag CT, Gladman DD. Sensitivity of the classification of psoriatic arthritis criteria in early psoriatic arthritis. Arthritis Rheum 2007;57:1560-3

10. Johnson SR, Goek ON, Singh-Grewal D, et al. Classification criteria in rheumatic diseases: a review of methodologic properties. Arthritis Rheum 2007;57:1119-33.
11. Pedersen OB, Junker P. On the applicability of the CASPAR criteria in psoriatic arthritis. Ann Rheum Dis 2008;67:1495-6.

12. Pedersen OB, Svendsen AJ, Ejstrup L, Skytthe A, Junker P. The occurrence of psoriatic arthritis in Denmark. Ann Rheum Dis 2008;67:1422-6.

13. Doran MF, Pond GR, Crowson CS, O'Fallon WM, Gabriel SE Trends in incidence and mortality in rheumatoid arthritis in Rochester, Minnesota, over a forty-year period. Arthritis Rheum 2002;46:625-31.

14. Shbeeb M, Uramoto KM, Gibson LE, O'Fallon WM, Gabriel SE. The epidemiology of psoriatic arthritis in Olmsted County, Minnesota, USA, 1982-1991. J Rheumatol 2000;27:1247-50.

15. Thumboo J, Uramoto K, Shbeeb MI, et al. Risk factors for the development of psoriatic arthritis: a population based nested case control study. J Rheumatol 2002;29:757-62.

16. Pattison E, Harrison BJ, Griffiths CE, Silman AJ, Bruce IN Environmental risk factors for the development of psoriatic arthritis: results from a case-control study. Ann Rheum Dis 2008;67:672-6.

17. Wilson FC, Icen M, Crowson CS, McEvoy MT, Gabriel SE, Maradit Kremers H. Incidence and clinical predictors of psoriatic arthritis in patients with psoriasis: a population-based study. Arthritis Care Res 2008; in press.

18. Ali Y, Tom BD, Schentag CT, Farewell VT, Gladman DD. Improved survival in psoriatic arthritis with calendar time. Arthritis Rheum 2007;56:2708-14.

19. Morgan C, Lunt M, Bunn D, Scott DG, Symmons DP. Five-year outcome of a primary-care-based inception cohort of patients with inflammatory polyarthritis plus psoriasis. Rheumatology Oxford 2007;46:1819-23

20. Kane D, Stafford L, Bresnihan B, FitzGerald O. A prospective, clinical and radiological study of early psoriatic arthritis: an early synovitis clinic experience. Rheumatology Oxford 2003;42:1460-8.

J Rheumatol 2009;36:213-5; doi:10.3899/jrheum.081242 